УДК 69

DOI $10.21661 / \mathrm{r}-475162$

И.С. Вахобов

НОВЫЙ ВИД ТЕПЛОГЕНЕРИРУЮЩЕГО

ОТ СОЛНЕЧНЫХ ЛУЧЕЙ УСТРОЙСТВА

Аннотация: в данной статье рассматриваются способы использования солнечной энергии для обогрева здания и разработки нового устройства для генерачии тепла от солнечных лучей. Автором представлены два вида использования солнечной энергии.

Ключевые слова: Солнце, энергия, генерация, теплоноситель, время, луч, вода, жилой дом.

\title{
I.S. Vahobov
}

\section{NEW TYPE OF HEAT GENERATING FROM THE SUN'S RAYS DEVICE}

Abstract: this article discusses how to use solar energy to heat a building and develop a new device for generating heat from the sun. The author presents two types of solar energy usage.

Keywords: Suns, energy, generation, heat carrier, time, ray, water, residential building.

Использование солнечной энергии для обеспечения потребностей человека используется с древних времен, так как оно является одной из главных средств в жизни. Использование солнечной энергии также широко используется для отопления домов и существует два вида использования солнечной энергии:

- активный;

- неактивный.

Активная система - это использование солнечной энергии через солнечные батареи и солнечные коллекторы и ее хранение на теплоаккумуляторе.

Неактивная система - использование солнечного света с помощью окон и ориентация расположения здания, а также аккумулирование тепла за счет толщины стен. 
Использование солнечной энергии это не новая отрасль, потому что она давно используется в Австралии, Израиле, Японии, США и другие страны.

Использование солнечной энергии в значительной степени экономично и экологично, а также является источником возобновляемой энергии.

Основываясь на всестороннем изучении недостатков и преимуществ существующего оборудования, мы рекомендуем новое оборудование, работающее с использованием солнечной и водным теплоносителем. Данное устройство имеет такие преимущеста над другим существующего оборудования:

- имеет малую площадь;

- приём всех видов прямых и диффузионных солнечных лучей;

- быстрое нагревание системы отопления;

- высокая температура;

- защита от замораживания;

- независимо от темпоратуры воздуха внешнего пространства оно производит тепло от солнечного света.

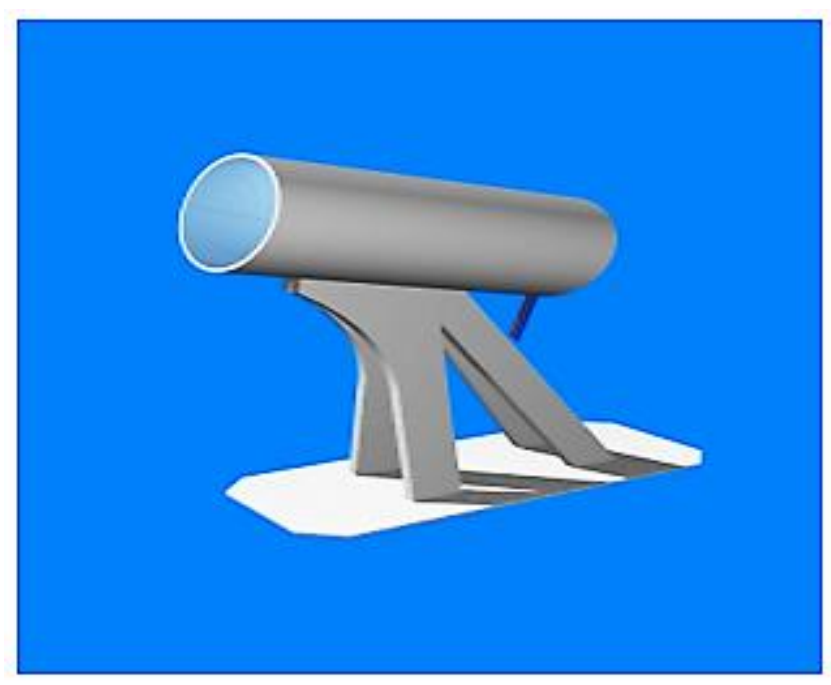

Рис. 1. Солнечное устройство 


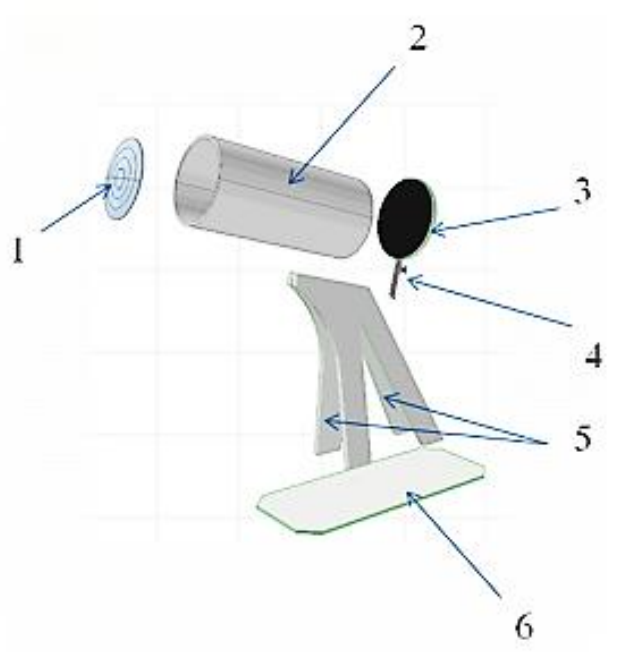

Рис. 2. Части солнечного устройства

Устройство состоит из таких частей:

1. Собирающая линза.

2. Kopnyc.

3. Пустотельный диск, покрытый селективным покритием.

4. Трубы для горячей и холодной водь.

5. Стойки.

6. Onopa.

Пустотельный диск с селективним покритием служит для приёма солнечной энергии отдачи эенргия на теплоносител или вода. Пустотность внутри диска заполняется водой во время работы обородувания.

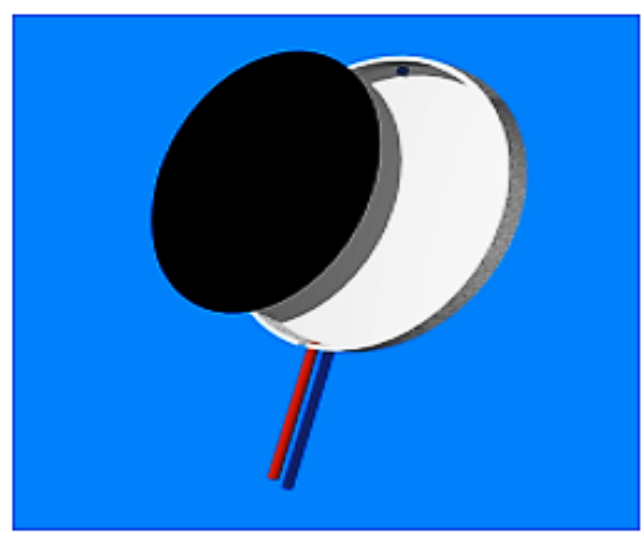

Рис. 3. Пустотельный диск 
Селективные покрытия - это оптические покрытия, создаваемые на поверхности элементов солнечных энергетических установок с целью снижения в них радиационных тепловых потерь [10].

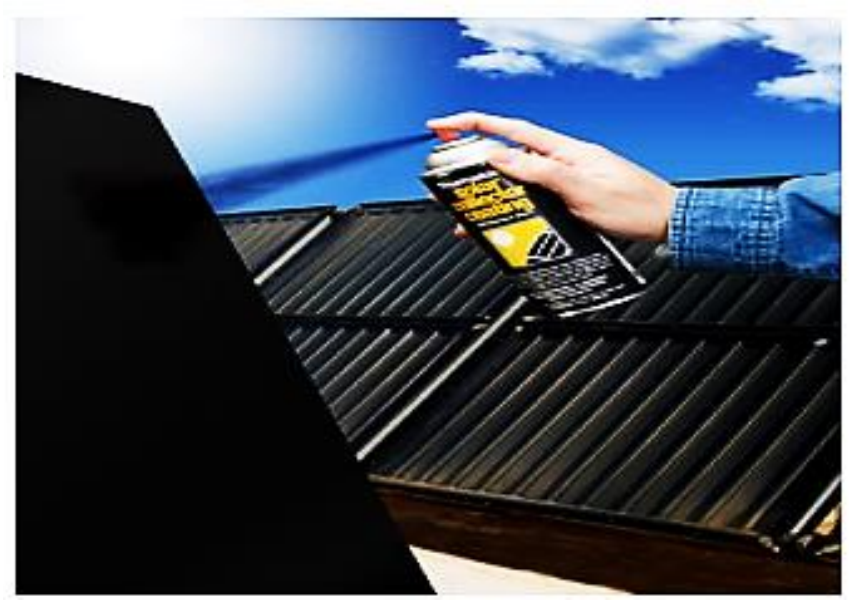

Рис. 4. Нанесение селективного покрытия

Принцип работы устройства заключается в том, что, когда солнечные лучи падают на линзу, линза собирает солнечные лучи в одно место и десятки раз увеличивает темпаратуру, потом пустотельный диск переводит тепло солнечних лучей на теплоноситель. В нашем случае мы использовали воду, мы можем на этом устройстве вместо воды использовать незамерзающую жидкость для повышения эффективности работы устройства. Одним из других преимуществ устройства является то, что оно является термостойким, за исключением внешней температуры солнечный прибор генерирует тепло. Разрез обородувания показан на рисунке 5.

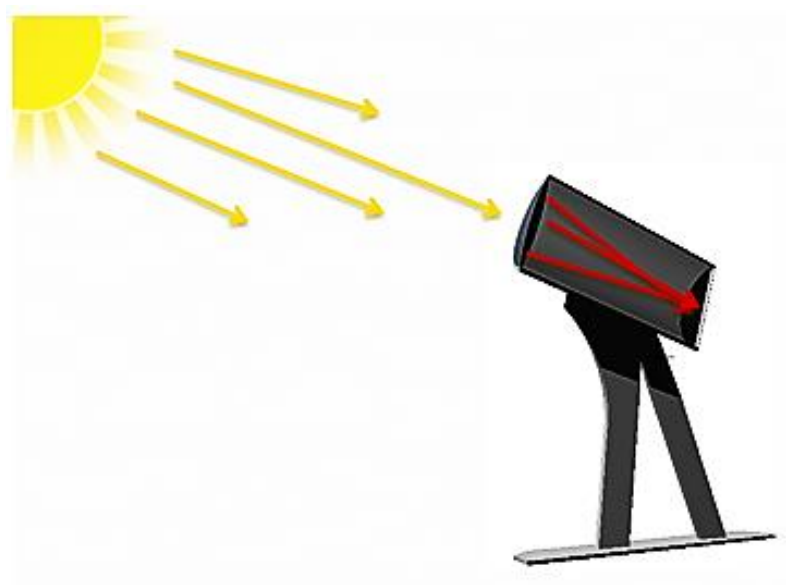

Рис. 5. Разрез обородувания 
Затем устройство подключается к системе отопления жилого дома.

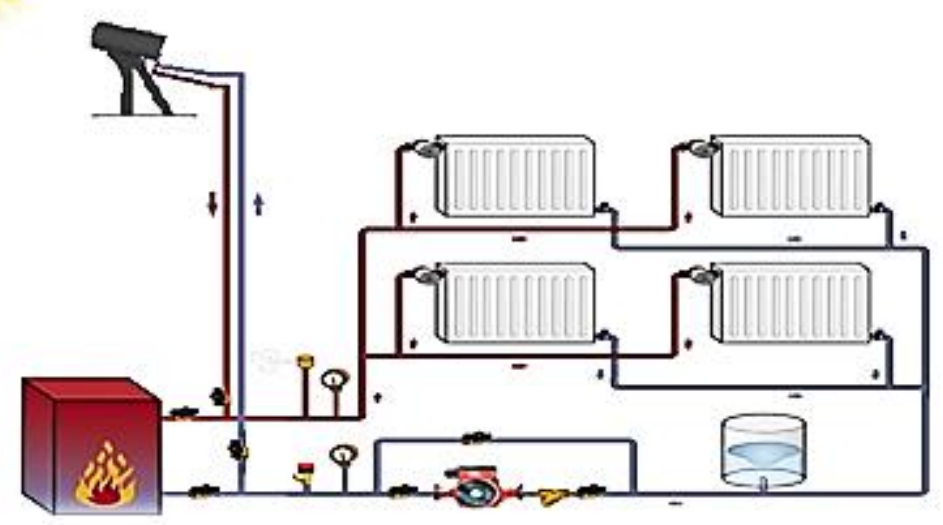

Рис. 6. План солнечного подключения обородувания к системе отопления жилого дома

Используя это оборудование, мы можем сэкономить другие источники тепла (электричество, газ, уголь и дрова) в зимние месяцы до 35-40\%. Летом с помощью этой системы мы можем подавать горячую воду, что снижает нагрузку на электроэнергию до 70-80\%.

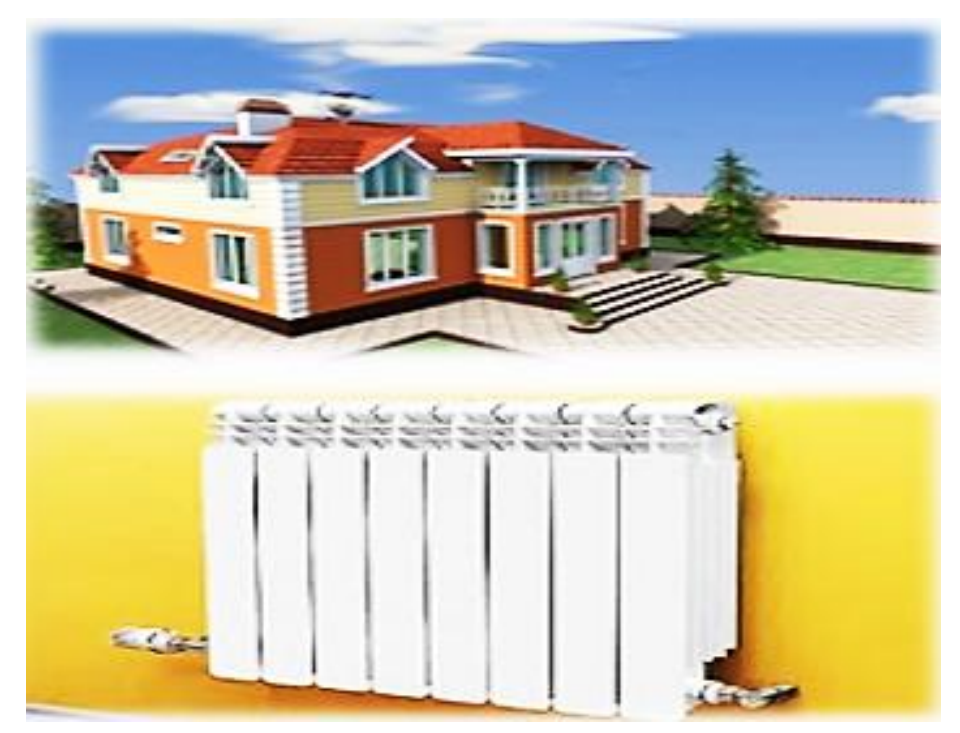

Рис. 7. Жилой дом с солнечным устройством

Экспериментальный расчет оборудования по модели

Во время экспримента с моделью разработанного оборудования было определено, что это устройство за 10 минут поднимает температуре воды от $23^{\circ} \mathrm{C}$ 
до $40-50^{\circ} \mathrm{C}$. В связи с наличием простых и упрощенных устройств модель оборудования является приблизительным показателем оборудования.
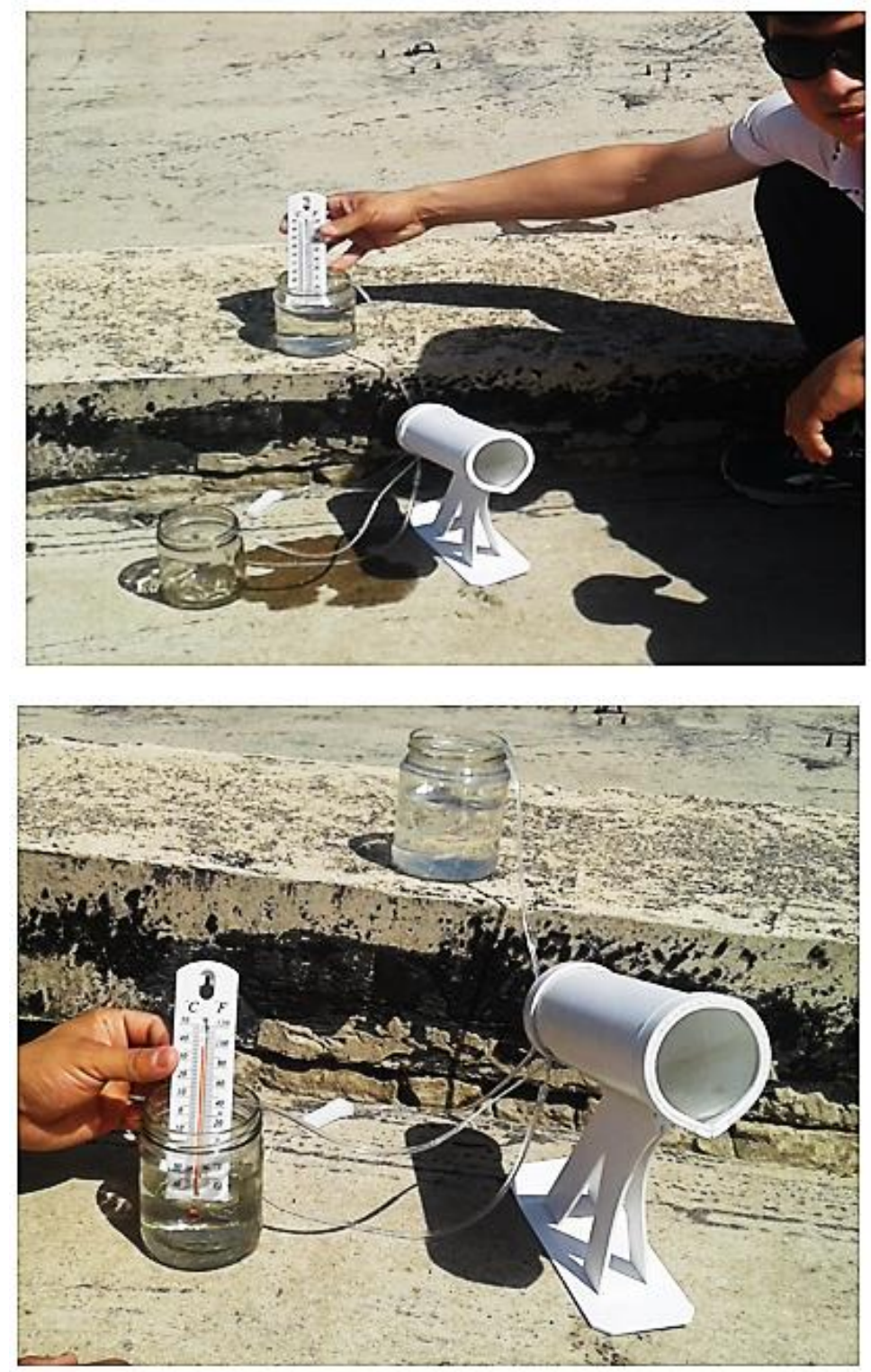

Рис. 8. Ход эксперимента с моделью

С данной полученной от модели данного оборудования мы можем определять реалный размеры оборудования для отопления жилого дома и нагревательного элемента системы отопления.

В модели разрабатываемого устройства мы используем линзу диаметром 6,5 см, его толщина 0,8 см, линза является основной частью оборудования.

Исходя из наших оценок, мы решили что при увеличении модель оборудования в 10 раз и собирает её от качественных и приназначенных для солнечних систем материалов мы можем обеспечить теплом жилого дома. В 
среднем система отопления квартиры имеет от 180 до 250 литров воды, в то время как мы в 10 раз увиличиваем, и модернизируем обородувание, мы можем нагреть систему отопления в диапазоне от 36 до 40 минут до 55-60c.

\section{Список литературы}

1. Ахмедов Р.Б. Нетрадиционные и возобновляемые источники энергии. М.: Знание, 1988.

2. Алексеев В.В. Солнечная энергетика / В.В. Алексеев, К.В. Чекарев. - М.: Знание, 1991. - 64 с.

3. Калинин Ю.Я. Нетрадиционные способы получения энергии / Ю.А. Калинин, А.Б. Дубинин. - Саратов: СПИ, 1983. - 70 с.

4. Лабунцов Д.А. Физические основы энергетики. - М.: Изд-во МЭИ, 2000.

5. Маров М.Я. Планеты Солнечной системы / М.Я. Маров. - М.: Наука, 1981. $-256 \mathrm{c}$.

6. Мировая энергетика: прогноз развития до 2020 г. / Пер. с англ. - М.: Энергия, 1980. - 255 с.

7. Муругов В.П. Методология развития автономных энергосистем в сельском хозяйстве с использованием возобновляемых источников энергии / В.П. Муругов, В.М. Каргиев. - СПб., 1993.

8. Нетрадиционные источники энергии. - М.: МЭИ, 1983.

9. [Электронный ресурс]. - Режим доступа: www.jumhuriyat.tj

10. [Электронный ресурс]. - Режим доступа: www.wikipedia.org

11. [Электронный ресурс]. - Режим доступа: www.leworld.org

12. [Электронный ресурс]. - Режим доступа: www.durahshon.tj

13. [Электронный ресурс]. - Режим доступа: www.homsol.org

\section{References}

1. Akhmedov, R. B. (1988). Netraditsionnye i vozobnovliaemye istochniki energii. M.: Znanie.

2. Alekseev, V. V., \& Chekarev, K. V. (1991). Solnechnaia energetika., 64. M.: Znanie. 
3. Kalinin, Iu. Ia., \& Dubinin, A. B. (1983). Netraditsionnye sposoby polucheniia energii., 70. Saratov: SPI.

4. Labuntsov, D. A. (2000). Fizicheskie osnovy energetiki. M.: Izd-vo MEI.

5. Marov, M. Ia. (1981). Planety Solnechnoi sistemy. M.: Nauka.

6. (1980). Mirovaia energetika., 255. M.: Energiia.

7. Murugov, V.P., \& Kargiev, V. M. (1993). Metodologiia razvitiia avtonomnykh energosistem $\mathrm{v}$ sel'skom khoziaistve $\mathrm{s}$ ispol'zovaniem vozobnovliaemykh istochnikov energii. $\mathrm{SPb}$.

8. (1983). Netraditsionnye istochniki energii. M.: MEI.

9. . Retrieved from www.jumhuriyat.tj

10. . Retrieved from www.wikipedia.org

11. . Retrieved from www.leworld.org

12. . Retrieved from www.durahshon.tj

13. . Retrieved from www.homsol.org

Вахобов Исроилходжа Самиевич - ассистент кафедры Политехнического института Таджикского технического университета им. академика М.С. Осими, РеспубликаТаджикистан, Худжанд.

Vahobov Isroilhodzha Samievich - assistant of the department of the Polytechnic Institute of the Tajik Technical University named after academician M.S. Osimi, Republic of Tajikistan, Khujand. 